\title{
Evaristo Valle (1873-1951): inicios en la prensa gráfica
}

Inocente Soto Calzado

Universidad de Málaga

\section{RESUMEN}

El pintor Evaristo Valle comenzó su carrera artística con una presencia en diversas revistas gráficas. Su trabajo en Blanco y Negro en 1898, sus portadas para Madrid Cómico en 1901 o su dibujo en Alma Española en 1904, desconocidos hasta el momento, hacen replantear los datos de su propia biografía.

\section{PALABRAS CLAVE:}

Evaristo Valle; Revistas gráficas; Blanco y Negro; Madrid Cómico; Alma Española.

\section{ABSTRACT}

The painter Evaristo Valle began his artistic career with a presence in various graphic magazines. His work in Blanco y Negro in 1898, their covers for Madrid Cómico in 1901 or his drawing in Alma Española in 1904, unknown until the moment, make rethink data for their own biography.

\section{KEY WORDS:}

Evaristo Valle; Illustrated reviews; Blanco y Negro; Madrid Cómico; Alma Española. 
Evaristo Valle (1873-1951) es sin duda uno de los pintores asturianos que han dado a la historia del arte español una obra con personalidad e idiosincrasia, donde el dibujo y el color se unen en un perfecto equilibrio ${ }^{1}$, imposible sin grandes dosis de talento. Encuadrado en los expresionismos de inicios del nuevo siglo, en paralelo a otros grupos nacionales y europeos ${ }^{2}$, sus maneras sobre el lienzo y el papel se fueron gestando en paralelo a su devenir vital, caracterizado por su extrema sensibilidad. Su obra sobre papel en la prensa gráfica precede a su dedicación a la pintura y está en íntima relación con la importancia que la literatura tiene en la vida y en la obra del artista, con la importante ayuda de dos personalidades tan contrapuestas como Leopoldo Alas, Clarin (1852-1901), y Luis Bonafoux Quintero (1855-1918), dos escritores enfrentados $^{3}$ y que, sin embargo, estuvieron al lado del pintor en diferentes momentos.

Su biografía primera fue escrita por el historiador Enrique Lafuente Ferrari (1898-1985), amigo para el que redactó muchos de sus recuerdos, y continuada por el periodista Francisco Carantoña Dubert (1926-1997), director del diario gijonés El Comercio, donde Valle publicó en la primera década del siglo XX algunos de sus trabajos gráficos. Los estudios más actuales han conseguido matizar las primeras informaciones y fijar más correctamente algunas cronologías ${ }^{4}$, y la tesis doctoral de Gretel Piquer Viniegra, presentada a comienzos de 2016, ha culminado una serie de trabajos donde quedaban patentes la superación del naturalismo y las características anticipadoras de una obra cercana al postsimbolismo ${ }^{5}$.

Nacido en Gijón, hijo de una familia numerosa, tras la temprana muerte del padre comienza a desempeñar diversos oficios y acaba trabajando como dibujante para la Litografía Artística, cuyo dueño era José Antonio Moré García de la Uz (1839-1935), emprendedor empresario que dota

1 VILLA PASTUR, Jesús, Historia de las artes plásticas asturianas, Ayalga Ediciones, Gijón, 1977, p. 194.

2 REYERO, Carlos; FREIXA, M., Pintura y escultura en España, 1800-1910. Cátedra, Madrid, 2005, pp. 402-403.

3 MARTÍNEZ CACHERO, José María, Hijos de la crítica: un enfrentamiento que hizo historia, GEA, Oviedo, 1991.

4 VALLINA VALLINA, Alicia, Evaristo Valle (1873-1951). Confluencias entre su obra pictórica y su obra literaria, Tesis doctoral, UCM, Madrid, 2014, p. 29.

5 PIQUER VINIEGRA, Gretel, "Evaristo Valle y Región. Revista de Asturias: Crisis, regeneracionismo y paisaje", en Mirando a Clio: el arte español espejo de su historia: actas del XVIII Congreso del CEHA, Universidad de Santiago de Compostela, Santiago de Compostela, 2012. a su taller con los últimos adelantos técnicos, fruto de sus viajes al extranjero ${ }^{6}$.

Hay un primer intento de establecerse en $\mathrm{Pa}$ rís, capital cultural europea del momento, en 1896, cuando contaba con 23 años ${ }^{7}$, pero su nulo conocimiento del idioma propició la vuelta a España en pocos meses.

En 1897 aparecen las primeras caricaturas conocidas, en La Saeta, de Barcelona, un semanario ilustrado nacido en la última década del siglo. Mudable como cualquier proyecto gráfico, siempre al azote del tiempo y de los tiempos, la revista estaba en su año VIII, con Pedro Motilba como administrador, imprimiéndose en la Tipografía La Académica en un formato pequeño de 25,5 x 17,5 cm, con 24 páginas; comenzaba lentamente a mostrar sus contenidos sicalípticos, con las jóvenes sugerentes plasmadas en las portadas por Francisco Gómez Soler (c.1860-1899) o las fotografías femeninas de Leopold-Emile Reutlinger (1863-1937). Entre sus colaboradores literarios se encontraban los escritores más cotizados del momento, como Leopoldo Alas, Emilia Pardo Bazán (1851-1921), Eusebio Blasco Soler (1844-1903) o Alfonso Pérez Gómez-Nieva (1859-1931). Clarín, amigo de la familia, a quien Valle declara en sus recuerdos conocer, admirar e incluso temer en sus divertidas polémicas religiosas con los sacerdotes a la mesa ${ }^{8}$, publicará en La Saeta entre enero y marzo del año 1897 cuatro de sus famosos Paliques periodísticos. Evaristo es un joven de 24 años, sin experiencia previa en el mundo gráfico tremendamente competitivo de final de siglo; las ilustraciones de La Saeta en ese momento están copadas por la fotografía, los grabados baratos procedentes de la industria editorial francesa y los dibujos de artistas locales, como el mencionado Gómez Soler o el realista Josep Passos Valero (1862-1928) acompañando las narraciones, o el dibujo cómico de Joaquín Xaudaró Echau (1872-1933), ya todo un profesional ${ }^{9}$, por lo que parece evidente que sin una recomendación el joven asturiano no hubiera llegado a debutar en la publicación barcelonesa. Valle publicará en tres

6 LIDÓN MARTÍNEZ, Concepción, La litografía industrial en el norte de España de 1800 a 1950. Aspectos históricos, estéticos y técnicos, Trea, Gijón, 2005, pp. 141-144.

7 LAFUENTE FERRARI, Enrique, La vida y el arte de Evaristo Valle, Diputación, Oviedo, 1963, p. 54.

8 VALLE, Evaristo, Recuerdos de la vida del pintor, Trama editorial, Madrid, 2000, pp. 45-52.

9 CASADO CIMIANO, Pedro, Diccionario biográfico de ilustradores españoles del siglo XIX, Ollero y Ramos, Madrid, 2006, p. 215. 
números de junio y julio ${ }^{10}$ varios chistes gráficos cuya base es la actualidad política del momento ${ }^{11}$, apoyándose gráficamente en la caricatura, con personajes que tienden a la macrocefalia y con una preocupación tonal, con un trabajo minucioso a la vez que ágil del tramado de grises, buscando el apoyo de las luces. Firma E. VALLE y también EVARISTO VA$L L E$, en mayúsculas. Su capacidad a la hora de plasmar los personajes protagonistas de las noticias candentes, como William McKinley (1843-1901) o Francisco Silvela (1843-1905), colaboran en la calidad de las viñetas; utiliza incluso textos periodísticos como pie del dibujo para interpretarlos gráficamente, haciendo que el sentido figurado de una metáfora o una comparación literaria se convierta en visual manteniendo su interpretación literal (Fig. 1). Desde la semiótica se define este tipo de trabajo como iconizaciones de expresiones verbales consolidadas en el habla común ${ }^{12}$, y la amalgama visual producida no deja de tener relación con los primeros postulados del surrealismo.

En 1898 volverá a aparecer en la prensa española, en este caso en Madrid, en las páginas de la publicación Blanco y Negro, que había aparecido en 1891 para convertirse en poco tiempo en el prototipo de semanario gráfico de calidad dependiente de una empresa periodística ${ }^{13}$. La revista, con un formato de $27,5 \times 19,5 \mathrm{~cm}$ y 24 páginas, ya se había ocupado en varias ocasiones de Émile Zola (1840-1902) desde que en enero la publicación de su artículo J'accuse lo pusiera en el ojo del huracán, encontrándose entre sus páginas continuas referencias al asunto Dreyfus y al proceso al escritor. En el primer número de marzo ${ }^{14}$, completando las ilustraciones de una página titulada La Condena de Zola, compuesta por grabados de otros periódicos, se inserta la caricatura del gran literato francés, firmada en esta ocasión en su ángulo inferior derecho EVARISTO del VALLE. El joven artista está a la vez buscando formas y firma, pues presenta la figura también macrocéfala pero aban-

10 La Saeta, Barcelona, año VIII, n 344, 24/6/1898; n 346, 8/7/1898; no 349, 29/7/1898.

11 ADÚRIZ, Patricio, "Perfil de Evaristo Valle en 1907", en Evaristo Valle. Caricaturas, humor gráfico y otras ironias (92-93). Fundación Museo Evaristo Valle, Gijón, 1984, p. 92.

12 GASCA, Luis; GUBERN, Roman, El discurso del cómic, Cátedra, Madrid, 2001, p. 400.

13 SÁNCHEZ VIGIL, Juan Miguel, Revistas ilustradas en España. Del Romanticismo a la guerra civil, Trea, Gijón, 2008, p. 21.

14 Blanco y Negro, Madrid, no 357, 5/3/1898.

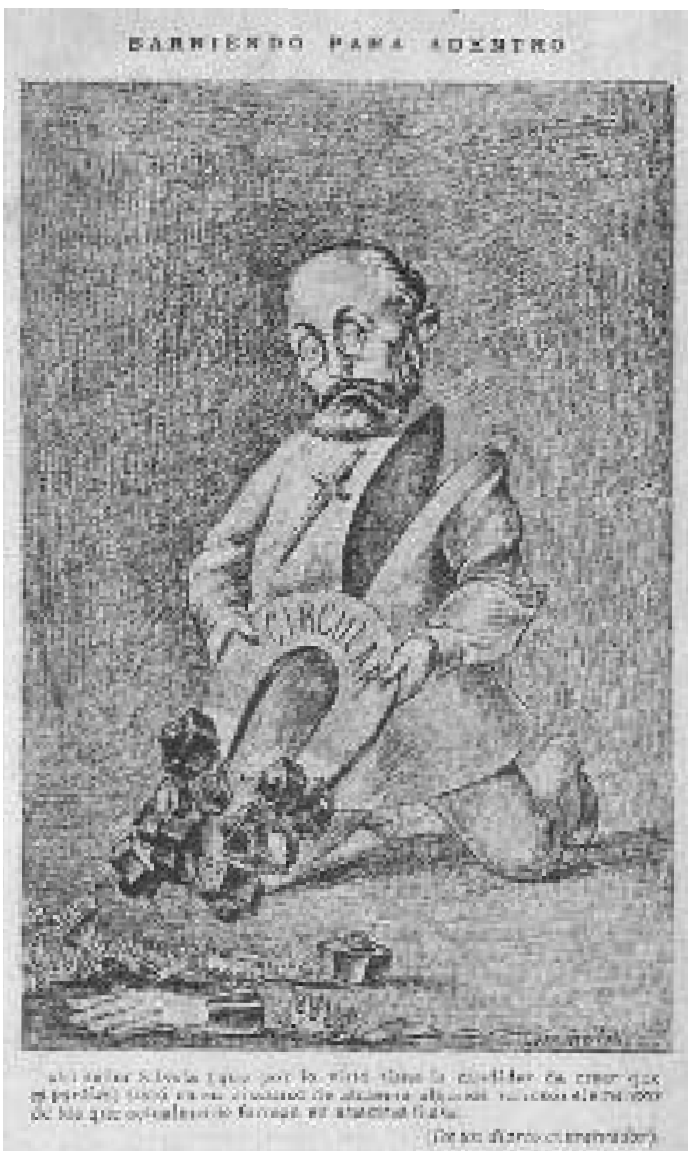

Fig. 1. Evaristo Valle. Barriendo para adentro. Fotograbado en $L a$ Saeta, Barcelona, año VIII, nº 349, 29/7/1897, s. p. Col. BASL, Málaga.

donando la técnica anterior por la de la aguada, aunque conceptualmente se apoya en parecidos mecanismos creativos, jugando con la iconicidad del lenguaje al acompañar al dibujo de rótulos como el de Yo soy el hombre más grande de la Francia sobre la pechera de Zola -saca pecho con su literatura- y hojas caídas bajo sus pies, que ha sacado también literalmente de su chistera, con la frase Yo acuso, traducción del título del alegato del escritor en la famosa portada del diario L'Aurore (Fig. 2).

Al final del año de 1898 parece ser el momento en el que decide volver a París. Apoyado en el conocimiento del oficio de dibujante litógrafo se presenta en una litografía, Maison Camus, donde obtiene trabajo de forma discontinua (cuando escasea la faena es el primero en salir despedido de una plantilla de medio centenar de operarios). Entabla conocimiento y relación con el dibujante Daniel Urrabieta Vierge (1851-1904), hemipléjico a sus cuarenta y siete años pero apasionado de su arte, generoso en la amistad y el apoyo al joven asturiano de veinticinco años. La imagen de la enfermedad de 


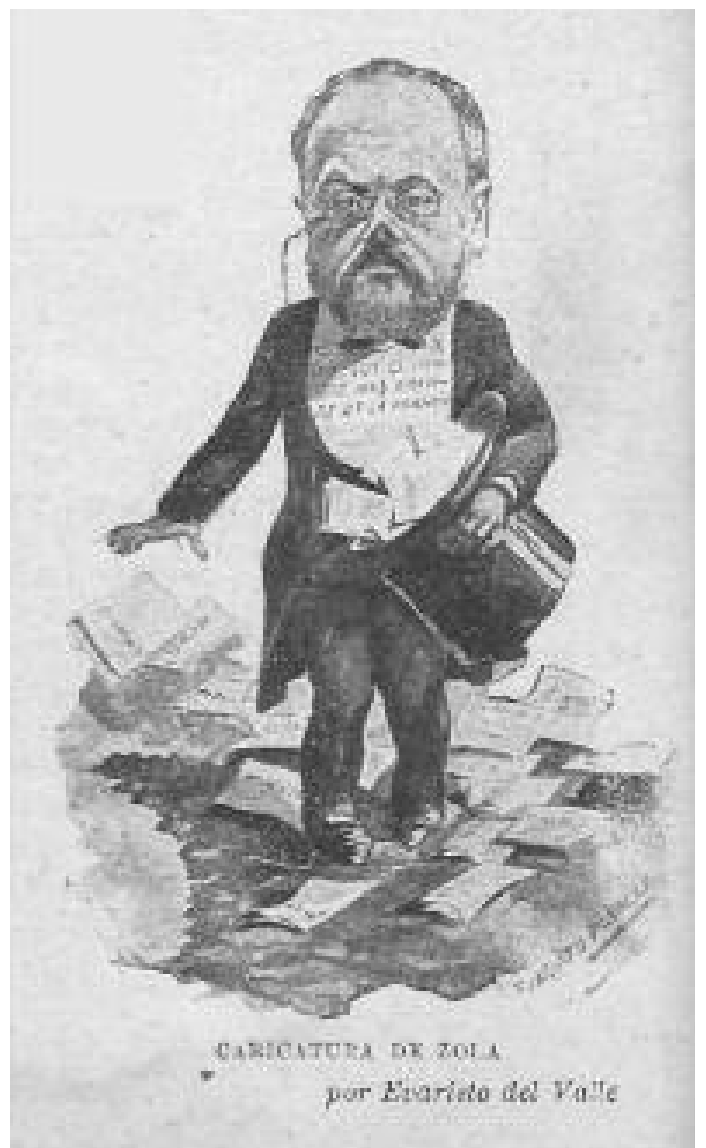

Fig. 2. Evaristo Valle. Caricatura de Zola. Fotograbado en Blanco $y$ Negro, Madrid, no 357, 5/3/1898. Col. BASL, Málaga.

Urrabieta causaría un fuerte impacto en su personalidad hipersensible. Valle sobrevive durante el primer año del siglo realizando carteles, ilustraciones y muestras de tienda, gracias a un compañero de trabajo de origen armenio, representante artístico que le aconseja hacer de forma profesional la labor que hace en el taller en los tiempos muertos. Se conocen dos de dichas ilustraciones ${ }^{15}$, impresas en una de las más prestigiosas revistas gráficas, donde publicaba con cierta asiduidad Henri de Toulouse-Lautrec (1864-1901). Le Rire, fundada en 1894 y dirigida por Arsène Alexandre (1859-1937) ${ }^{16}$, era una revista de edición cuidada y de colaboradores escogidos, aunque ninguno de ellos fijo durante mucho tiempo. Tenía un día a la semana para recibir a los dibujantes y analizar sus trabajos. Ese

15 SOTO CALZADO, Inocente, Dibujantes con París al fondo. Picasso y las revistas ilustradas, Fundación Picasso Museo Casa Natal , Málaga, 2014, pp. 49-53.

16 SOLO; SAINT-MARTIN, Catherine; BERTIN, Jean-Marie, Dico Solo. Plus de 5000 dessinateurs de presse et 600 supports, Aedis, Vichy, 2004, p. 740. día especial fue plasmado por el dibujante Heidbrinck en 1898 en una curiosa ilustración titulada Le jour des dessinateurs au Rire, donde se ve un tumulto de artistas carpeta en ristre en una abarrotada oficina. Si eran admitidos y el autor no había publicado anteriormente, se reproducian primero a un cuarto de página, en blanco y negro, dejando el color y la página entera a los artistas ya curtidos ${ }^{17}$.

El primer trabajo, firmado en esta ocasión $\mathrm{Del}$ $V A L L E$, está reproducido a media página, a mucho mayor tamaño que su compañero de maquetación. Publicado en agosto de 1900, su debut en Le Rire con el título de Un duel a mort está resuelto sólo con línea, con un trazo ágil, controlado, descriptivo y a la vez dinámico, contradiciendo la comentada necesidad de corporeidad de sus trabajos ${ }^{18}$, aunque sea a título de excepcionalidad. El artista divide la narración en seis cuadros iguales, manteniendo en todos ellos el mismo punto de vista. Serán los personajes, en este caso los duelistas, los que se muevan en ese escenario teatral, observados por los padrinos de ambos. La ceremonia, ridícula desde el comienzo en sus poses, acaba peor aún cuando los dos que se habían batido a muerte terminan dándosela uno al otro al mismo tiempo, para desconsuelo de los padrinos y para terminar de subrayar sarcásticamente la necedad del acto. Aunque la narración pide alguna escena más de enlace, especialmente entre el penúltimo y último cuadro, la historia está muy lograda gráfica y visualmente, con la sabiduría de contar en el tiempo.

Su segundo trabajo, casi cinco meses más tarde, es otra composición a media página. Bajo el título de Six grands peintres, se presentan seis viñetas donde evidentemente el tema es el del pintor, personaje humorístico que tendrá con los años incluso su propio modelo icónico en las revistas. Cada uno de los cuadros es un pequeño mundo, lleno de ínfimos detalles que colaboran al conjunto, hablando claramente de la capacidad del artista y de sus dotes de observación. Magníficamente reproducibles, como no se podía esperar menos de un dibujante litógrafo, utiliza sólo la línea o distribuye de forma mecánica los grises mediante líneas paralelas, concentrando su atención a veces en las expre-

17 BACHOLLET, Raymond, Juan Gris dibujante de prensa. De Madrid a Montmartre, El Viso, Madrid, 2003, p. 220.

18 PLANELL RODRÍGUEZ, Joaquín, "Evaristo Valle, dibujo y pintura: notas de aproximación”, en Evaristo Valle (1873-1951). Dibujos, Ministerio de Cultura, Madrid, 1986, pp. 43-60, p. 43. 
siones y otras en los gestos, en un conjunto agradable y variado, seleccionado con muy buen criterio por la redacción de la revista ${ }^{19}$.

El último trabajo francés se publica en enero de 1901, precisamente cuando el artista está en España. El fin de la Exposición Universal y la falta de trabajo en la ciudad precipitan su vuelta a la ciudad natal. El artista acabará trabajando, según sus biografías, en la litografía Mencía y Paquet, que la literatura especializada denomina Compañia Asturiana de Artes Gráficas, fundada en el año 1902 por iniciativa de Julio García Mencía y Alberto Paquet García-Rendueles junto a otros socios burgueses ${ }^{20}$. Mencía había sido director artístico del taller de Moré, donde Valle comenzó en el oficio, por lo que quiso contar con el joven en la nueva empresa.

Todas las fuentes fechan en 1902 su viaje a Madrid, fascinado por el Museo del Prado, y el propio pintor ordenó así sus recuerdos:

Para poder sostenerme al lado de tanta maravilla quise dibujar en algún periódico y no lo he conseguido. Trabajé sólo dos dias en un taller de litografía; porque el tercero en vez de ir a la litografía, me fui al Museo del Prado. Todo esto duró sólo dos semanas porque aprisa me volvi a Gijón, solicitado por una nueva litografía que allí se instaló. ${ }^{21}$

Sin embargo, el hallazgo de dos portadas de la revista Madrid Cómico del año 1901 con su firma contradicen esa temporalidad y el declarado fracaso del artista, así que las dos semanas debieron serlo de 1901 y la calidad del trabajo depositado en la redacción permitió que este viera la luz pocos meses después. Madrid Cómico nació en 1880 como periódico semanal festivo e ilustrado, con una vida larga y llena de éxitos. Su fundador fue Miguel Casañ, y su director en los inicios Sinesio Delgado García (18591928). A final de 1897 la revista iba a vivir uno de sus cambios, siendo adquirida por Bernardo Rodríguez Serra (1872-1902), terminando el 25 de diciembre de 1897 una gloriosa época con Sinesio Delgado como director de 775 números desde 1883, con una difusión de casi ocho mil ejemplares semanales ${ }^{22}$. Leopoldo Alas había sido un

19 Le Rire, París, año VI, nº 302, 18/8/1900, p. 10; año VII, $\mathrm{n}^{\circ} 322,5 / 1 / 1901$, p. 11.

20 LIDÓN MARTÍNEZ, Concepción, La litografía industrial, opus cit., p. 145.

21 VALLE, Evaristo, Algunos datos de mi vida, Fundación Museo Evaristo Valle, Gijón, 2000, p. 2.

22 GONZÁLEZ FREIRE, José Manuel, "Medio siglo en Madrid. Memorias de un escritor público de tercera fila", Anales del Instituto de Estudios Madrileños, XLV, CSIC, Madrid, 2005, pp. 673-699, p. 675.

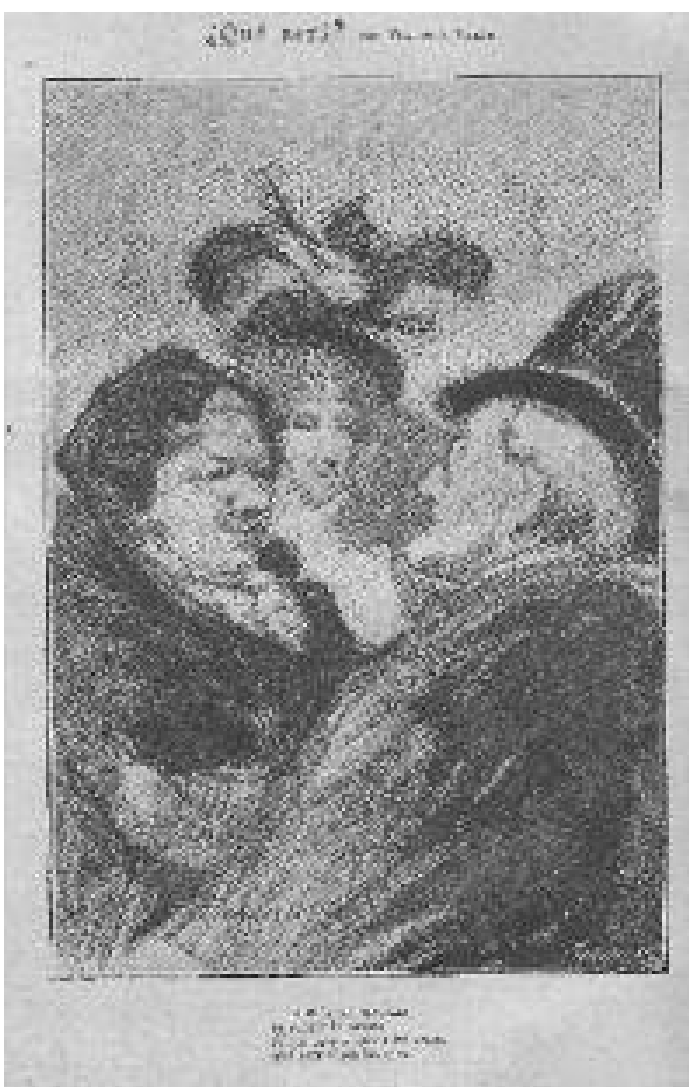

Fig. 3. Evaristo Valle. ¿Qué será? Fotograbado en Madrid Cómico, Madrid, año XXI, n 13,30/3/1901, portada. Col. BASL, Málaga.

colaborador literario fijo además de destacado, y su director durante un corto período de tiem$\mathrm{po}^{23}$. Sinesio Delgado volvería a la cabecera a partir de septiembre de 1899, cuando aparezca un nuevo propietario, José de la Loma, director con el que comienza a publicar Valle en el longevo semanario de 8 páginas y $33,5 \times 24 \mathrm{~cm}$.

Su primera portada lleva fecha de 30 de marzo de 1901, casi al comienzo del año, y bajo el título de ¿Qué será? (Fig. 3) muestra una escena con tres personajes, envolviendo al grupo con una magnífica composición, en una visión muy cercana que permite observarlos mirándose unos a otros o hurtándose las miradas, con un anciano de levita y chistera en primer término dirigiéndose a la pareja de mujeres de paseo, donde las dos sonríen con miradas muy diferentes en sus edades, ojos abiertos de alcahueta para la mayor y párpados bajados de supuesta inocencia en la menor. El grafismo es ágil, vigoroso, con una decisión que se detiene en las expresiones

23 RODRÍGUEZ DE LA FLOR, José Luis, "Estudio introductorio", en El Madrid Cómico de Clarín, Edición facsímil, Plus Ultra, Madrid, 1992, pp. XIII-XXX. 


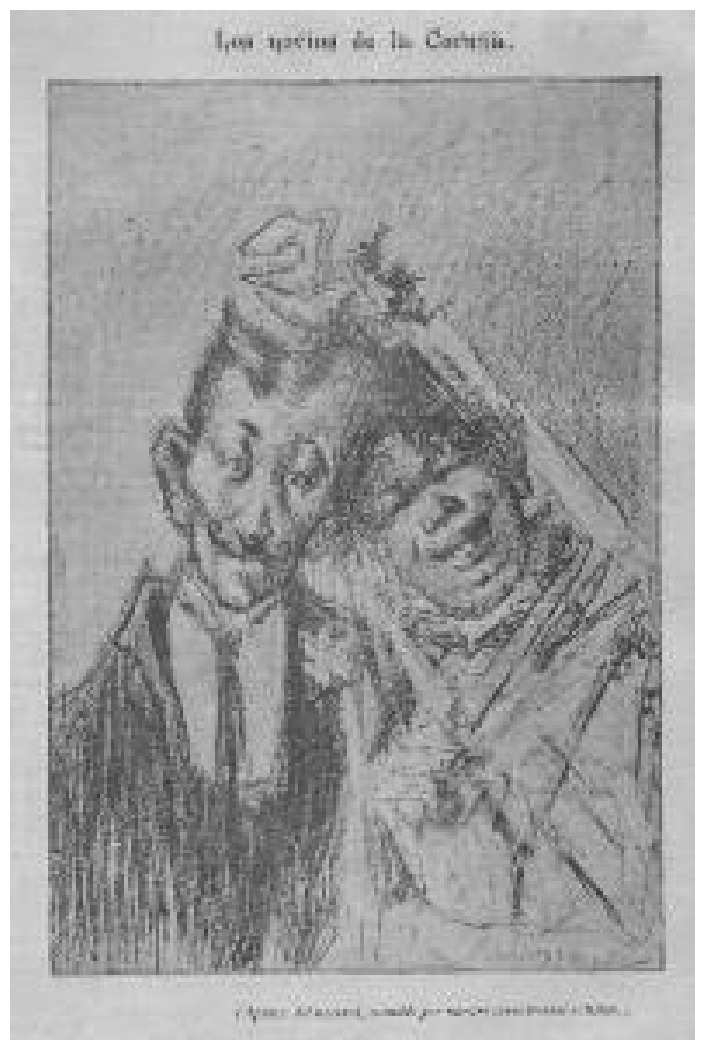

Fig. 4. Evaristo Valle. Los novios de la Coruña. Fotograbado en Madrid Cómico, Madrid, año XXI, n² 29, 20/7/1901, portada. Col. BASL, Málaga.

para sacar de los rostros todas las historias que pretenden silenciar. Aquí Valle ha olvidado la caricatura gruesa de sus primeros trabajos para dejar claro sobre el papel su inusitada capacidad de narración y de observación en una versión principio de siglo de La Celestina. Un dibujo superior y con una multiplicidad de lecturas al que no favorece la simplona cuarteta que como pie pretende explicarlo: La niña se ruboriza,/ se sonrie la mamá.../iVaya usté a saber las cosas/ que este viejo las dirá! ${ }^{24}$

La segunda portada, fechada el 20 de julio del mismo año ya con Carlos de Batlle como siguiente director, tiene toda una literatura tras ella, pero por encima de esas palabras está el dibujo de nuevo soberbio de Valle. Muestra una atribulada pareja, recién casada o a punto de ello, formando un elocuente triángulo compositivo, donde la mujer ocupa la mayor parte del espacio y donde la expresión cariacontecida del hombre poco tiene que ver con la sonrisa y placidez de la fémina, así como los tamaños y actitudes de ambos. Como en la anterior, sorprende gratamente la decisión y fuerza del trazo, que se

24 Madrid Cómico, Madrid, año XXI, n 13, 30/3/1901, portada. vuelve pausado cuando debe de plasmar la elocuencia de los rostros, apoyándose en unas magníficas luces y sombras (Fig. 4). Ha sido titulado Los novios de la Coruña, y el texto al pie dice: (Apunte del natural, remitido por nuestro corresponsal artístico) ${ }^{25}$. Hay que tomar con precaución los textos de dicho número, más jocosos que de costumbre, pues en él se trataba con humor, aunque de una forma chusca, el suceso real que había acontecido en Galicia, una boda entre dos mujeres que como se puede suponer levantó un escándalo y sirvió para llenar páginas de diferentes publicaciones ${ }^{26}$. La redacción se había valido del dibujo de Valle y de otros tres de Leal da Cámara (1876-1948), que en aquel momento se encontraba trabajando en París, para supuestamente ilustrar un acontecimiento recogido en otras publicaciones como El suceso ilustrado, que había dedicado a las dos mujeres protagonistas, Marcela y Mario (bautizada Elisa), la portada del número 9, del 14 de julio de 1901, con una fotografía de la pareja, además de explicar toda la historia, inmortalizando al cura y a los tres médicos que se encargaron de examinar al falso hermafrodita. El dibujo de Valle había sido convertido por Madrid Cómico en la versión jocosa de la pareja, y en las páginas interiores habian redondeado el supuesto reportaje con Personajes episódicos a cargo del lápiz de Leal da Cámara: El cura que los casó, El médico que los reconoció, La madre que los parió. Evidentemente, ni los dibujos de Valle ni los de Cámara tenían relación real con el suceso ni pretendían plasmarlo de ninguna forma, siendo con seguridad anteriores a todo ello. Para rematar la chanza, en el interior la redacción realiza una parodia de la sección Nuestros grabados que el escritor Carlos Luis de Cuenca (1849-1927) tenía en la publicación La Ilustración Española y Americana, firmado por un ficticio Carlos Luis de Soria, presentando a Valle como corresponsal en La Coruña y a Cámara trasladándose hasta allí desde París para tomar apuntes, terminando con un explícito e inmodesto $Y$ si non è vero...è ben trovato.

Es bastante extraño que Valle no supiera de estas dos publicaciones, pero lo que es cierto es que al ser halladas demuestran que la visita a Madrid debió ser a finales de 1900 o principios de 1901, y no en 1902; el artista, como le ocurrió en otras ocasiones, abandonó el escenario an-

\footnotetext{
25 Madrid Cómico, Madrid, año XXI, n 29, 20/7/1901, portada.

26 GABRIEL FERNÁNDEZ, Narciso de, Elisa y Marcela: más allá de los hombres, Libros del Silencio, Barcelona, 2010.
} 
tes de los aplausos, sin ni siquiera conocer la acogida de su obra.

Evaristo Valle decide, ya establecido en Gijón, dedicarse a la pintura, frente al paisaje de su niñez, y se suceden exposiciones en 1902 y en 1903. Del encuentro con el periodista José Francos Rodríguez (1862-1931), director del Heraldo de $\mathrm{Ma}$ drid, y su decidido apoyo saldría una pensión anual, que le concedería el Ayuntamiento de Gijón para trasladarse a París, suprimida después con la excusa de no haberlo hecho de inmediato y haber fijado su residencia en Noreña, aunque un cáustico Bonafoux adivinaba otros motivos:

Sí: yo también me pongo en todo, y comprendo a los concejales que suprimieron la pensión de Valle. Tendrán otras atenciones más transcendentales y perentorias, tal vez, una corrida de toros o un banquete de concejales ${ }^{27}$.

Entre su oculta época gráfica española y su incipiente nueva oportunidad parisina va a aparecer un dibujo suyo en la revista Alma Española, publicación símbolo del regeneracionismo y cuna de muchos de los escritores adscritos posteriormente a la denominada generación del 98. Alma Española nació en noviembre de 1903 para terminar en abril de 1904, sin completar un año de existencia con sus 23 números. En la época en la que Valle publica su obra el número consta de 16 páginas ilustradas, con unas medidas de 34 x 24,5 cm, y su contraportada ya había dejado de imprimirse a todo color para dedicarse por entero a la publicidad. A pesar de su corta historia, su edición pasa por varios períodos, donde se destaca siempre un nombre que ya hizo méritos en Madrid Cómico, José Martínez Ruiz (1873-1967), Azorín, como pieza fundamental, por lo menos en la dirección literaria ${ }^{28}$. Uno de los colaboradores junto a Azorín en la primera época será Luis Bonafoux, que ostentaba el cargo en aquel entonces de corresponsal en París del diario Heraldo de Madrid, y su última entrega coincidirá en la revista con la autobiografía para la sección Juventud Triunfante de Francos Rodríguez, auténtico valedor de Valle. Bonafoux escribió cuatro crónicas para Alma Española, y la última data del 20 de diciembre de 1903, en su número 7, por lo cual es extraño que el dibujo de Evaristo, con el pie Luis Bonafoux.-Caricatura de Valle, aparezca dos meses después del fin de la colaboración ${ }^{29}$, en un número donde no

27 CANO, Jose Luis, La España de Bonafoux, Libertarias, Madrid, 1990, p. 232.

28 O'RIORDAN, Patricia, "Prólogo", en Alma Española, Edición facsímil, Turner, Madrid, 1978, pp. VII-XIV, p. VIII.

29 Alma Española, Madrid, año II, nº 16, 21/2/1904, p. 6.

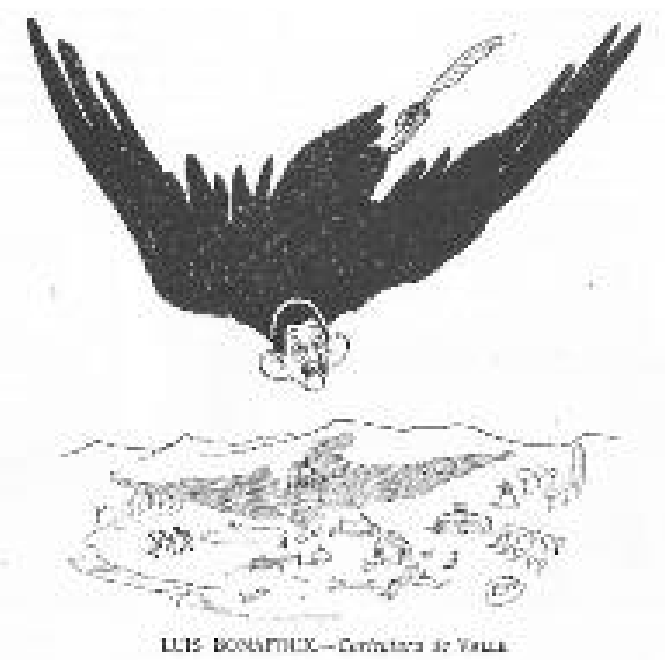

139

Fig. 5. Evaristo Valle. Luis Bonafoux. Fotograbado en Alma Española, Madrid, año II, n 16, 21/2/1904, p. 6. Facsímil. Col. BASL, Málaga.

hay ninguna otra alusión al sarcástico escritor, probando que la obra de Valle había quedado de nuevo a la espera en la redacción. Se trata, efectivamente, de una caricatura, pero bastante diferente de los primeros trabajos, mostrando al escritor, el temido ${ }^{30}$, zoomorfizado, no como una víbora, como se le conocía ${ }^{31}$, sino con la apariencia de un ave rapaz al acecho, pluma en ristre, sobrevolando un paisaje de avenidas arboladas, fuentes, plaza de toros, edificios monumentales y diversas escenas con figuras (Fig. 5). Por los símbolos que pueden intuirse en la composición parece tener bastante relación con el segundo artículo publicado por Bonafoux en Alma Española, titulado Desde París ${ }^{32}$, donde se habla de un toro regalado por el embajador inglés al presidente de la República francesa, anécdota aprovechada por el periodista para recordar la pérdida de torería de España, su triste realidad en el concierto internacional. Bonafoux habría conocido al artista asturiano en París a principios de noviembre de 1903, a su llegada, y le había dedicado un artículo de su sección París al día, repleto de digresiones marca de la casa sobre los más variopintos temas, pero con los dos últimos párrafos dedicados a Valle, hablando de sus figuras atormentadas, admirables en su verdad y en su sentimiento, adivinando su valía en los trabajos que le muestra:

30 LAPUYA, Isidoro L., La bohemia española en París a fines del siglo pasado, Renacimiento, Sevilla, 2001, p. 175.

31 DICENTA SÁNCHEZ, Jose Fernando, Luis Bonafoux la "vibora de Asnieres”. CVS, Madrid, 1974.

32 Alma Española, Madrid, año I, n 4, 29/11/1903, p. 5. 
Porque es un pintorazo con temperamento, ideas propias, entusiasmos, energias, con cosas, en $\mathrm{fin}^{33}$.

Los primeros intentos de Valle en la prensa ilustrada habían sido pasos valiosos en su carrera, muy mal aprovechados, cuando no desconocidos para el propio artista, carentes de la continuidad necesaria. En sus comienzos había conseguido publicar en La Saeta y Blanco y Negro, pero su intento de establecerse en París rompió el futuro de dichas oportunidades; cuando publica en una revista tan prestigiosa como Le Rire, abandona París; en Madrid no tiene la paciencia de ver impreso su trabajo, volviendo a Gi- jón ignorante de su éxito en Madrid Cómico, y el dibujo para Alma Española lo realiza cuando ya está de nuevo en París, produciéndose su publicación también con Valle en la capital francesa, con grandes dificultades en el día a día. Volverá posteriormente en diversas ocasiones a la caricatura y la ilustración, sin abandonar dicho campo, mostrando siempre su cariño y sus dotes para el papel, pero de una forma esporádica y con la pintura como guía básica de su devenir artístico. Si hubiera recogido en ese primer momento de su carrera los frutos de su dedicación a la prensa gráfica, su éxito hubiera sido merecidamente más rápido y fácil.

33 BONAFOUX, Luis, "Un pintor asturiano", Heraldo de Madrid, Madrid, año XIV, nº 4743, 14/11/1903, portada. Dentro de la problemática cronológica de la biografía de Valle, Lafuente Ferrari data este artículo sobre 1906, pero las hemerotecas permiten precisar su fecha exacta. 